\title{
DRIVERS AND BARRIERS OF USING INTRENET OF THINGS FOR SUCCESSFUL LEAN IMPLEMENTATION IN CONSTRUCTION PROJECTS IN SRI LANKA
}

\author{
SANDAGOMIKA, N.M.G.H. ${ }^{1}$, SANDANAYAKE, Y.G. ${ }^{2} \&$ EKANAYAKE, B.J. ${ }^{3}$ \\ 1,2,3 University of Moratuwa, Colombo, Sri Lanka \\ 1helaminisandagomika94@gmail.com, ${ }^{2}$ yasangee@yahoo.com,3 biyankaje@gmail.com
}

\begin{abstract}
With the rising impact of technological advancements within all sectors, there is an increase in interest among construction industry practitioners to integrate novel technologies collaborated with concepts. Lean is one such concept, which has received growing attention of construction companies. However, past researchers have identified many barriers for successful lean implementation in global construction context, where, technological approaches seem to be a success factor. Many experts have identified Internet of Things (IoT) as an enabler for the lean implementation in construction, which is undoubtedly lacking in the Sri Lankan context. Hence, this paper aims to investigate the drivers and barriers for using IoT for successful lean implementation in Sri Lankan construction industry. Seven semi structured interviews with experts in IoT and lean construction were conducted under the qualitative approach for data collection to achieve the research aim. Findings highlighted increased product and process quality; reduced unnecessary delays in construction process; reduced unnecessary costs; enhanced inventory management system; and increased site safety as key drivers, whereas, expensive devises and high cost of implementation; resistance to change; lack of internet coverage, IT facilities and compatibility issues; difficulties to adapt due to lack of knowledge and skills; security and privacy issues; and lack of innovative culture were identified as key barriers of using IoT for successful lean implementation in Sri Lankan construction industry. Findings revealed the several similarities in drivers and barriers of using IoT for lean construction implementation both in global and Sri Lankan context.
\end{abstract}

Keywords: Lean Construction; Internet of Things (IoT); Drivers; Barriers

\section{Introduction}

Lean is a management approach, which focuses on process improvement, satisfying customer needs and achieving the best financial results for a particular business (Salah \& Rahim, 2019). Lean concept has been implemented by growing numbers of construction companies who intended to reduce the cost to meet high value of productivity and overcome the competitiveness while ultimately achieving the minimisation of seven types of wastes namely overproduction, over process, transportation, defects, motion, inventory and waiting (Salah \& Rahim, 2019). But many researchers worldwide have identified major barriers under managerial, cultural, technical and implementation related aspects that have an impact on successful lean implementation (Mostafa, et al., 2013). Although some barriers can be overcome through human approaches, the technological approaches seem to be important in order to reach successful implementation of lean concept in construction industry. Supporting this, Sarhan et al. (2018) highlighted that technological barriers are highly affecting the successful implementation of lean construction.

Among large numbers of technological advancements, Louis and Dunston (2018) identified that Internet of Things (IoT) has the potential to enhance the implementation of lean construction. Sens (2013) described IoT as the internet protocol technology, which is rapidly spreading to new domains. IoT has been growing widely by emerging with the lean construction as contractors are tending to spend their resources and efforts on technological tools in order to advance their work and win over their competitors (Zankoul, et al., 2018). According to Ghi and Rossetti (2016), many factors are driving the utilisation of IoT for successful lean implementation in construction industry, which are seeking the attention of contractors, several barriers are also impacting the usage of IoT applications in successful lean construction implementation.

Although, Senaratna and Wijesiri (2008) ensured that lean construction implementation is suitable and applicable to the Sri Lankan construction industry, Thilakarathna (2012) identified that Sri Lanka is behind the successful implementation of lean construction due to the lack of suitable implementation framework. In the Sri Lankan context, Ranadewa, Sandanayake and 
Siriwardena (2018) identified lack of networking and collaboration as one of the root causes for the lack of successful implementation of lean concept in the construction projects in Sri Lanka. Moreover, novel technological concepts such as IoT are also available and currently practicing within the construction industry in Sri Lanka. However, there is a lack of evidence on the drivers and barriers of the application of IoT for the successful lean implementation in Sri Lankan construction projects. Therefore, this paper aims to identify the drivers and barriers of using IoT for successful implementation of lean concept in construction projects in Sri Lanka.

\section{Application of IoT in Implementation of Lean Construction}

Although many advantages can be achieved by lean implementation, still the sense of how to successfully implement the lean concept is lacking in most of the companies (Jadhav, et al., 2014). Some organisations are trying to implement lean in the environment, where it does not suit, whereas some other organisations are struggling with conventional approaches in the implementation process (Kolberg \& Zühlke, 2015). In this context, few researchers stated that these issues can be addressed through the technological solutions (Louis \& Dunston, 2018; Rossini, Costa, Tortorella, \& Staudacher, 2019; Sanders et al., 2016; Zankoul et al., 2018). Considering the Sri Lankan context, Ranadewa, Sandanayake and Siriwardena (2018) elaborated the lack of new tools and technologies as a cause for non-value adding activities, which hinder the successful lean implementation in construction projects. Further, Louis and Dunston (2018) clearly stated that IoT has the capability to enhance and overcome the barriers of the implementation of lean construction.

Some researchers have provided evidence on how IoT can be used to support the successful implementation of lean in different industries. Sanders et al. (2016) identified collaborative manufacturing, better communication mechanisms, synchronisation of data, item tagging, wireless tracking of goods, smart reallocation of order, standardised interfaces, virtual organisationssynergetic cooperation as some of the areas for which IoT is used in lean manufacturing. Buer, Strandhagen and Chan (2018) stated that some fundamental lean tools such as Value Stream Mapping (VSM) is a manual "pen-paper process", which is quite a challengeable process in data collection perspective. However, J.C. Chen and Chen (2014) identified that VSM can be enhanced through some key components of Industry 4.0 such as IoT through real time data collection. Gubbi, Buyya, Marusic and Palaniswami (2013) stated that IoT can reduce different types of wastes that comes under lean concept such as waiting, unnecessary inventory, overproduction and the defectives. Further, Dave, Koskela and Kiviniemi (2013) identified that some lean construction management systems such as VisiLean or KanBIM can be improved by using IoT standards, thus enhancing interoperability across construction projects between all major information systems and organizations. Although it is obvious that IoT can be applied to enhance lean in construction industry, there are drivers and barriers for IoT application.

\section{Drivers and Barriers of using IoT for Lean Implementation in Construction Industry}

This section presents the literature synthesis on drivers and barriers, which impact the application of IoT for successful lean implementation in construction industry.

\subsection{DRIVERS OF USING IOT FOR LEAN CONSTRUCTION IMPLEMENTATION}

There are many conceptual and empirical researches that have investigated how IoT could enhance the performance dimensions of the lean practices. Ghi and Roseetti (2016) identified reduced cost as one of the major drivers whereas Ma, Wang and Zhao (2017) highlighted the same benefit in their empirical investigation. Moreover, the nature of flexibility in construction projects is another driving factor which tends the construction professionals to use IoT in lean implementation (Sanders, et al., 2016; Kolberg \& Zühlke, 2015; Wang, et al., 2016). Increased productivity of the construction projects has been highlighted as another major driving factor (Sanders, et al., 2016; Wang, et al., 2016). 
Increasing the quality of the completed construction projects when using the IoT applications to lean construction implementation has drawn the attention of many construction professionals (Ghi and Roseetti, 2016; Jayaram, 2016). Further, Kolberg and Zühlke (2015) and Wagner, Herrmann and Thiedev (2017) highlighted the reduced inventory as another major driving factor. Unnecessary inventory reduction can be considered as one of the major benefits of lean construction where the IoT applications have the potential to enhance the reduction of inventory through IoT based inventory management system (Wang, et al., 2018). Moreover, the reliability has been highlighted by the researches as another driving factor (Ma, et al., 2017, Wagner, et al., 2017). Figure 1 illustrates the summary of driving factors of using IoT for lean implementation in the construction industry.

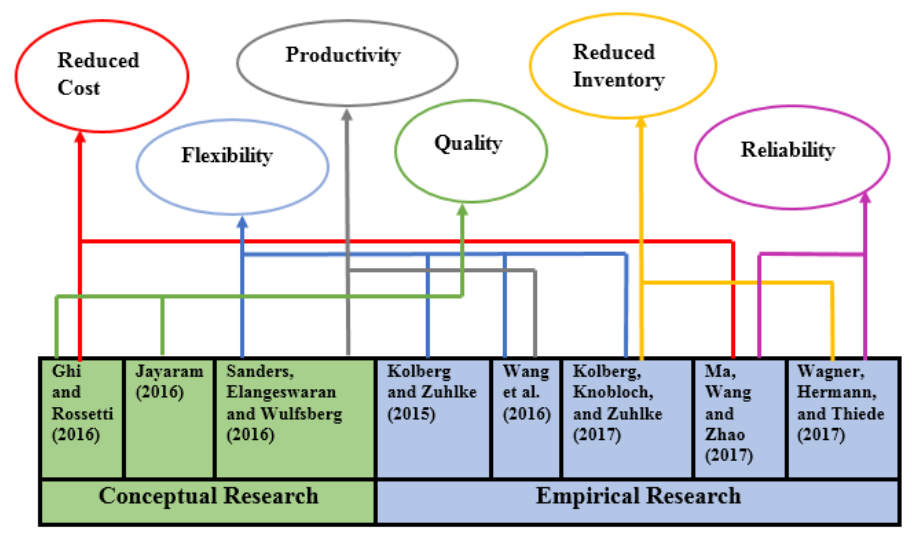

Figure 1: Drivers of using IoT for Successful Lean Implementation in Construction

\subsection{BARRIERS IN USING IOT FOR LEAN CONSTRUCTION IMPLEMENTATION}

Many researchers worldwide have highlighted the barriers of using IoT applications in global construction industry. However, there is lack of specific literature resources related to barriers of using IoT with related to the successful lean implementation in the global construction industry. The following table summarises the barriers that lean implementers faced when using IoT for lean implementation in different settings.

Table 1: Barriers in Using IoT for Successful Lean Implementation

\begin{tabular}{|c|c|}
\hline Barriers in IoT adaptation & Source \\
\hline Employment disruptions - a cause for a human job loss & $\begin{array}{l}\text { (Gnimpieba, et al, } \\
\text { 2015) }\end{array}$ \\
\hline $\begin{array}{l}\text { Additional cost for implementation - also threats of } \\
\text { financial losses and no recovery of investments }\end{array}$ & (Heiskanen, 2017) \\
\hline $\begin{array}{l}\text { Organisational and process change - organization's } \\
\text { functions and patterns might be changing }\end{array}$ & $\begin{array}{l}\text { (Gnimpieba et al., } \\
\text { 2015) }\end{array}$ \\
\hline $\begin{array}{l}\text { Requirement of enhanced skills - highly qualified and } \\
\text { skilful human resources are required with prerequisite } \\
\text { knowledge }\end{array}$ & (Li et al., 2019) \\
\hline $\begin{array}{l}\text { Lack of clear comprehension about IoT benefits - as } \\
\text { several applications and technologies from IoT are still in the } \\
\text { development stage }\end{array}$ & (Turkes, et al., 2019) \\
\hline Lack of Internet coverage and IT facilities & (Fang, et al., 2016) \\
\hline $\begin{array}{l}\text { Security and privacy issues - due to the cybersecurity threat } \\
\text { and data privacy issues. }\end{array}$ & $\begin{array}{l}\text { (Maskuriy, et al., } \\
\text { 2019) }\end{array}$ \\
\hline $\begin{array}{l}\text { Lack of standards and reference architecture - as IoT } \\
\text { concept is novel concept }\end{array}$ & (Mueller, et al., 2017) \\
\hline $\begin{array}{l}\text { Seamless integration and compatibility issues - } \\
\text { difficulties in upgrading existing machinery and equipment suit } \\
\text { for IoT }\end{array}$ & (Li et al., 2019) \\
\hline $\begin{array}{l}\text { Legal and Contractual Uncertainty - become a legally } \\
\text { independent entity in the digitalisation process }\end{array}$ & (Turke \\
\hline
\end{tabular}




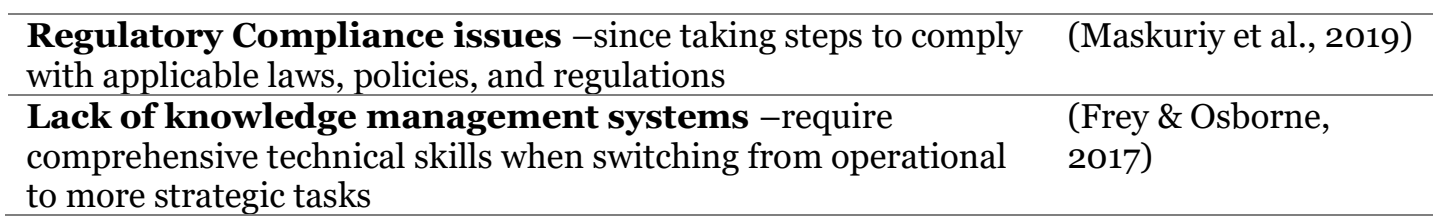

The identified drivers and barriers in the global context need to be explored for local context due to the lack of studies conducted in Sri Lanka. Hence, this paper aims to investigate the drivers and barriers of using IoT for successful lean implementation in Sri Lankan construction industry.

\section{Methodology}

An extensive literature review facilitated the researcher to strengthen the base of the research by congregating the prevailing knowledge around the research area. Thus, a comprehensive literature review was conducted to identify the use of IoT for successful lean implementation in construction projects, drivers and barriers of using IoT for successful lean implementation in global context through books, journals and conference proceedings.

Among several data collection techniques available, Punch (2005) highlighted interview method as one of the most commonly used data collection method when research embodies a qualitative approach. Considering the various types of interviews, semi-structured interviews were adopted as it allows the researcher to ask both structured and unstructured questions and facilitates clarifying doubts. Since the IoT and lean construction are advanced concepts and only few industry practitioners are aware of it, expert interview was conducted as the most suitable data collection method. Further, the number of experts were limited to few due to the IoT and lean concepts are grooming areas and so the experts are also limited. Hence, expert interviews were conducted using semi structured interview guidelines with seven experts in order to collect data to clarify how the identified drivers and barriers are impacting to the application of IoT for successful lean implementation in construction projects in Sri Lanka. Finally, data analysis was carried out through manual content analysis. Table 2 shows the profile of experts.

Table 2: Profile of the Experts

\begin{tabular}{|c|c|}
\hline Expert & Description \\
\hline E1 & $\begin{array}{l}\text { Executive Director having } 10 \text { years working experience in A reputed construction company, } \\
\text { which is an overseas construction arm. As this organisation entails with technology and they are } \\
\text { focusing on the lean implementation within their construction projects. }\end{array}$ \\
\hline E2 & $\begin{array}{l}\text { Construction Manager of one of the leading construction companies in Sri Lanka with } 11 \text { years } \\
\text { working experience. This company is one of the most innovative civil engineering organization } \\
\text { in Sri Lanka. }\end{array}$ \\
\hline E3 & $\begin{array}{l}\text { Assistant General Manager with } 10 \text { years of working experience in a well reputed construction } \\
\text { company. He is currently implementing lean concept in the site and further, doing some } \\
\text { researches on IoT applications with the intention of introducing them to their site. }\end{array}$ \\
\hline E4 & $\begin{array}{l}\text { Director with } 11 \text { years of working experience in a reputed consultancy company } \\
\text { in Sri Lanka. They are providing consultancy services on using the emerging } \\
\text { technologies and lean implementation. }\end{array}$ \\
\hline E5 & $\begin{array}{l}\text { Project QS of a one of the reputed ongoing construction projects Sri Lanka. He uses novel } \\
\text { technological solutions and lean in the project. }\end{array}$ \\
\hline E6 & $\begin{array}{l}\text { Director of one the leading consultancy company in Sri Lanka. He involved in implementing lean } \\
\text { concept and has knowledge on IoT applications in both local and foreign contexts. }\end{array}$ \\
\hline E7 & $\begin{array}{l}\text { Director of one the leading consultancy company in Sri Lanka and has both local and overseas } \\
\text { experience. This company is currently providing their consultancy services to the large numbers } \\
\text { of mega projects. }\end{array}$ \\
\hline
\end{tabular}

\section{Findings and Analysis}

The findings through the comprehensive literature review were referred to the experts through a semi structured interview guideline in order to identify the drivers and barriers impacting for the 
application of IoT for lean construction implementation. Following sections present the findings of the study.

\subsection{DRIVERS OF USING IOT FOR SUCCESSFUL IMPLEMENTATION OF LEAN CONSTRUCTION IN SRI LANKA}

The expert opinion on the impact of drivers of IoT adaptation to the construction projects of Sri Lanka, which was identified in literature synthesis was investigated through the expert interviews. Eight drivers were presented through the semi structured interview guideline and experts were questioned regarding their opinion on how these drivers are impacting the successful lean implementation in Sri Lankan construction projects.

Cost effectiveness was the first driver and one responded explained that "... minimise the unexpected failures or defective works in the construction process, so cost effectiveness would be a driving factor ...”. Moreover, some experts responded as, due to the proper planning and monitoring of the IoT system, it will be a cost-effective system as it will lead for the lesser of overproduction or over processing. The experts identified time saving as one of the major drivers due to proper planning and monitoring of the IoT system. Some experts specifically stated that "the proper planning incorporated with the just in time (JIT) delivery would save time. High quality of end product and service was another identified driver and according to some responses, high quality of the end product will be secured as IoT systems will always minimise the errors. Further, respondent expressed that "... they are having some platforms or systematic procedures to control the quality...”.

As per the idea of all the experts, improving site safety can also be considered as another driver of IoT adaptation towards successful lean implementation. The same idea of identifying threats, giving warnings, allowing site access only for the authorized people, avoid falling and injuries to labours was expressed by few of the respondents and since, the reduction of unnecessary motions, waiting and transportation can be achieved. Hence, it is evident that improving site safety is a driver of IoT which would lead more towards the successful implementation of lean concept in construction projects in Sri Lanka. Improving the image of the construction industry is another driver, which all the experts expressed positively that IoT concept will decrease defects and hence lead to uplift the image of the construction projects through innovative concepts. According to the expert's opinion, innovative products and designs also another driver which have a certain impact to the lean implementation through the waste minimisation in Sri Lankan construction projects. In that sense, some experts explained that IoT will surely guarantee the reliability of the designs and it will provide new ways to improve productivity and efficiency.

Reduction of wastes in and out of sites is another major driver identified by the experts and some experts mentioned that "the reduction of wastes in and out of sites happens due to the proper planning and monitoring system". As for the last driver named as proper inventory management identified in the literature synthesis, all the experts responded positively as it a driving factor to use IoT applications for the lean construction implementation. Therefore, in summary, drivers of IoT application for the successful lean implementation in construction projects in Sri Lanka can be identified as follows:

- Increase product and process quality

- Reduce unnecessary delays in construction process

- Reduce unnecessary costs

- Enhance inventory management system

- Increase site safety

5.2. BARRIERS OF IOT ADAPTATION FOR THE SUCCESSFUL IMPLEMENTATION OF LEAN CONSTRUCTION IN SRI LANKA 
A question based on the barriers of IoT adaptation was shown to all seven experts in order to capture their opinion on whether the identified barriers in literature in the global context for the adaptation of IoT in construction industry are also having an impact towards the successful lean implementation in the Sri Lankan construction projects. There were several barriers identified by the experts and some of the barriers were highlighted by all the seven respondents. Additional cost for implementation identified as one of the major barriers of IoT adaptation as the expensiveness of devises and cost of investment is considerably higher in IoT applications. Lack of clear comprehension about IoT benefits also highlighted by all the respondents and some experts stated that "... as these systems are linked with new technologies and hence people are not competent enough to deal with these new technologies...”. Lack of knowledge management system identified in the literature synthesis due to the requirement of comprehensive technical skills when switching from operations to more strategic tasks was another barrier highlighted by all seven experts. According to all the experts, lack of standards and reference architecture was another major barrier, which some experts explained that as it is a new concept, there are not any standards to be referred. Requirement of enhanced skills is another barrier encountered by the all seven respondents in IoT usage for lean implementation. In that sense some experts stated that "existing manpower might not have the adequate knowledge and competency level do deal with the new technological advancements".

Seamless integration and compatibility issues is another barrier explained by all the respondents. According to some experts "this will become a major barrier as there will be huge problems when we are upgrading the existing machineries while implementing the IoT concept". Security and privacy issues were another major barrier as the utilisation of IoT applications have the highest potential to lead to cybersecurity threats and data privacy issues. Some of the barriers were only accepted by the six experts and employment disruption was one of those barriers, which some experts highlighted as "due to the majority of worker's attitude to change with the technologies and automation processes, this can be a barrier". Organisational and process change can also be considered as another barrier and some experts evident this as "this happens due to the attitudes of the human and the top management of an organisation as people are not ready for a drastic change within their organisation or occupation". Moreover, lack of internet coverage and IT facilities, legal and contractual uncertainties and regulatory compliance issues have been identified by the experts, which can be impacting for the successful lean construction implementation.

Except to the barriers that the researcher incorporated to the interview guideline from literature synthesis, some respondents identified another four barriers that have the potential to impact the use of IoT to the successful implementation of lean construction. Specifically, all these barriers are related to the existing culture of the construction industry and those barriers can be stated as no learning culture attitude in Sri Lanka, rigid organizational culture, no innovative culture in the Sri Lankan construction industry and no research and development attitude in the construction industry to deal with new technological advancement. So, in summary, barriers for the use of IoT for the successful lean implementation in construction projects can be identified as follows:

- Expensiveness of the devises and high cost of implementation

- Resistance to change

- Lack of internet coverage, IT facilities and compatibility issues

- Difficulties to adapt due to lack of knowledge and skills

- Security and privacy issues

- Lack of innovative culture

\section{Conclusions and Recommendations}

Comprehensive literature review identified that lean concept can be collaborated with IoT to enhance the success of its implementation in construction industry. Numbers of IoT applications are currently available which are using to successfully implement lean construction within the 
global construction industry. Literature review highlighted that IoT applications, which spread rapidly to new domains can be used to overcome the barriers of successful lean. But, when using the IoT applications, there are several drivers and barriers that the construction professionals have to encounter with in the global context. Hence, this study was aimed to identify the drivers and barriers that are impacting for the successful lean construction implementation using IoT applications.

Literature synthesis has identified the IoT applications to the lean implementation in construction projects and numbers of drivers and barriers that are impacting the successful implementation of lean construction. In the analysis of collected data, drivers of the utilisation of IoT for the successful implementation of lean construction are also evidenced the importance of integrating IoT to the successful implementation. Increases product and process quality; Reduction of unnecessary delays in construction process; Reduction of unnecessary costs; Enhanced inventory management system; Increased site safety were some of the drivers highlighted by the experts. Barriers towards the application of IoT for successful lean implementation were highlighted by the experts as Expensiveness of the devises and high cost of implementation; Resistance to change; Lack of internet coverage, IT facilities and compatibility issues; Difficulties to adapt due to lack of knowledge and skills; Security and privacy issues; Lack of innovative culture in Sri Lanka.

Further, certain recommendations can be made through the findings of this research study for industry practitioners such as understanding the possible IoT applications that can be used for lean implementation in construction projects and key benefits of using IoT applications in lean implementation. Moreover, the industry practitioners can be recommended with to understand the barriers of using IoT applications for lean implementation in construction projects and getting prepared with the strategies to overcome them.

\section{References}

Buer, S.-V., Strandhagen , J. O. \& Chan, F. T. S., 2018. The link between Industry 4.0 and lean manufacturing: mapping current research and establishing a research agenda. International Journal of Production Research, 56(8), pp. 29242940.

Chen, J. C. \& Chen, K. M., 2014. Application of ORFPM System for Lean Implementation: An Industrial Case Study. International Journal of Advanced Manufacturing Technology, 72(5), pp. 839-852.

Dave, B., Koskela, L. \& Kiviniemi, A., 2013. Implementing Lean in construction, London: Classic House.

Fang, C., Liu, X., Pardalos, P. M. \& Pei, J., 2016. Optimization for a three-stage production system in the internet of things: procurement, production and product recovery, and acquisition. International Journal of Advance Manufacturing Technology, 83(5), pp. 689-710.

Frey, C. B. \& Osborne, M. A., 2017. The future of employment: how susceptible are jobs to computerization?. Technol. Forecasting Soc. Change, Volume 114, pp. 254-280.

Ghi, A. \& Rossetti, F., 2016. 4D Printing: An Emerging Technology in LeanManufacturing. s.l.:Springer, Cham. Gubbi, J., Buyya, R., Marusic, S. \& Palaniswami , M., 2013. Internet of Things (IoT) : a vision, architectural elements, and future directions. Future generation computer system , 29(7), p. 1645-1660.

Heiskanen, A., 2017. The technology of trust: how the Internet of Things and blockchain could usher in a new era of construction productivity. Construction Research and Innovation, 8(2), pp. 66-70.

Jadhav, R. S., Mantha, S. S. \& Rane, S. B., 2014. Exploring Barriers in Lean Implementation. International Journal of Lean Six Sigma, 5(2), pp. 122-148.

Jayaram, A., 2016. Lean six sigma approach for global supply chain. Noida, IEEE, pp. 89-94.

Kolberg, D. \& Zühlke, D., 2015. Lean automation enabled by industry 4.o technologies. IFAC-PapersOnLine , 48(3), pp. 1870-1875.

Li, J., Kassem, M., Ciribini, A. L. C. \& Bolpagni, M., 2019. A proposed approach integrating DLT, BIM, IoT and smart contracts: demonstarting using a simulated installation task. s.l., ICE , pp. 275-282.

Louis, J. \& Dunston, P. S., 2018. Integrating IoT into operational workflows for real-time and automated decisionmaking in repetitive construction operations. Automation in Construction, Volume 94, pp. 317-327.

Ma, J., Wang, Q. \& Zhao, Z., 2017. SLAE-CPS: Smart Lean Automation Engine Enabled by Cyber-Physical Systems Technologies. Sensors, 17(7), pp. 1500-1512.

Maskuriy, R. et al., 2019. Industry 4.0 for the construction industry-how ready Is the industry. Applied Science, 9(14), pp. 2819-2829.

Mostafa, S., Dumrak, J. \& Soltan, H., 2013. A framework for lean manufacturing. Production \& Manufacturing Research: An Open Access Journal, 1(1), pp. 44-64.

Mueller, E., Chen, X. L. \& Riedel, R., 2017. Challenges and requirements for the application of industry 4.0: a special insight with the usage of cyber-physical system. China Jornal of Mechanical Engineering, 30(5), pp. 1050-1057. Punch, K. F., 2005. Introduction to Social Research-Quantitative \& Qualitative Approaches. London: Sage publications. 
Ranadewa, K. A. T. O., Sandanayake, Y. G. \& Siriwardena, M., 2018. Enabling lean among small and medium enterprise (SME) contractors in Sri Lanka. Chennai, s.n., p. 392-401.

Rossini, M., Costa, F., Tortorella, G. L. \& Staudacher, A. P., 2019. The interrelation between Industry 4.0 and lean production: an empirical study on European manufacturers. The International Journal of Advanced Manufacturing Technology, 102(9-12), pp. 3963-3976.

Salah, S. \& Rahim, A., 2019. The integration of six sigma and lean. s.l.:Springer, Cham.

Sarhan, J. et al., 2018. Barriers to implementing lean construction practices in the Kingdom of Saudi Arabia (KSA) construction industry. Construction Innovation, 18(2), pp. 246-272.

Senaratna, S. \& Wijesiri, D., 2008. Lean construction as a strategic option: Testing its suitability and acceptability in Sri Lanka. Lean Construction Journal, 34(4).

Sens, J., 2013. IETF standardization in the field of the Internet of Things (IoT): A survey. Sensor and Actuator Networks, 2(2), pp. 235-287.

Thilakarathna, N., 2012. A preliminary literature review in to lean construction implementation. Colombo, s.n., pp. 345-354.

Turkes, M. C. et al., 2019. Drivers and barriers in using Industry 4.0: A perspective of SMEs in Romania. Processes,

Volume 7, pp. 153-173.

Wagner, T., Herrmann, C. \& Thiede, S., 2017. Industry 4.o impacts on lean production systems. s.l., Science Direct, pp. 125-131.

Wang, B. et al., 2016. Lean intelligent production system and value stream practice. Jiangsu, China, s.n., pp. $442-447$ Wang, M., Ma, Y., Sadiq, M. \& Al-Hussein, M., 2018. IoT-based Inventory Control System Framework for Panelized. s.l., Modular Building Institute.

Zankoul, E., Khoury, H., Salhab, . D. \& Antar, S., 2018. A review on Internet of Things Solutions for enhancing construction equipment fleet productivity. Slovenia, s.n., pp. 971-978. 